\title{
Intelligent decision support algorithm for distribution system restoration
}

\author{
Reetu Singh ${ }^{1 *}$, Shabana Mehfuz ${ }^{2}$ and Parmod Kumar ${ }^{3}$
}

\author{
${ }^{*}$ Correspondence: reetu. \\ jmi@gmail.com \\ 1 Jamia Millia Islamia, New \\ Delhi, Delhi, India \\ Full list of author information \\ is available at the end of the \\ article
}

\begin{abstract}
Distribution system is the means of revenue for electric utility. It needs to be restored at the earliest if any feeder or complete system is tripped out due to fault or any other cause. Further, uncertainty of the loads, result in variations in the distribution network's parameters. Thus, an intelligent algorithm incorporating hybrid fuzzy-grey relation, which can take into account the uncertainties and compare the sequences is discussed to analyse and restore the distribution system. The simulation studies are carried out to show the utility of the method by ranking the restoration plans for a typical distribution system. This algorithm also meets the smart grid requirements in terms of an automated restoration plan for the partial/full blackout of network.
\end{abstract}

Keywords: Distribution system, Fuzzy logic, Grey system theory, Power system restoration, Transformer loading

\section{Background}

India's blackout as two separate events on 30th and 31st July 2012, has forced the system design engineers to plan the restoration schemes which are more effective and efficient and takes into account the uncertainties involved in the transmission distribution network. Power system blackouts cannot be avoided. Their occurrence is rare, but their impact can be very serious. Further, the electric utilities also have loss of revenue. It is therefore essential to study, analyse and prepare the restoration plans in the event of tripping of a feeder or transmission line due to fault or other reasons (Fukuyama and Chiang 1995; Hsu et al. 1992; Hsiao and Chien 2000; Hsu and Kuo 1994; Lee et al. 1998; Ma et al. 1992). Some of the features of effective strategy plans are:

- The minimum number of consumers should be affected due to outage of the feeder.

- Power loss should be minimum on restoration of supply after blackout/feeder tripping.

- The structure of the radial network needs to be maintained as far as possible.

- The capacity of transformer, feeders, laterals and other network circuits should maintain and not exceed their capacity limits after restoration of the distribution network system.

- The critical consumers and loads should be given priority during strategy planning.

- For fast and techno economical solutions, there shall be ranking of the restoration plans in order to be followed by system operator.

(c) 2016 The Author(s). This article is distributed under the terms of the Creative Commons Attribution 4.0 International License (http://creativecommons.org/licenses/by/4.0/), which permits unrestricted use, distribution, and reproduction in any medium, provided you give appropriate credit to the original author(s) and the source, provide a link to the Creative Commons license, and indicate if changes were made. 
The outage of feeder needs to be isolated to restore the maximum possible consumer's load by restructuring the distribution network meeting the operational constraints and limits of feeder and equipments. In the present paper the criteria for selecting the restoration strategic plans are:

1. Minimizing the operation of switches.

2. Availability of supply to maximum consumer's load, and

3. Meeting the constraints and unconstrained criteria.

Tsai et al. (1993), Berdandon et al. (2011), Feltes et al. (2006), Liu and Lin (2012), Chen et al. (2001); Lotfifard et al. (2011), Lim et al. (2006) and Nagata and Sasaki (2002) present the various methods for reconfiguration of networks after blackout or feeder outage. However, a limited work is available based on fuzzy-grey relation ranking method. Further, in most of these research works, constraint related to distribution transformer has not been included. Transformer is an important source of supply and hence we have incorporated the constraint of transformer capacity limit besides the constraints related to distribution network, like feeders and laterals capacity limitations. In order to compare and verify the accuracy of the study, a prototype distribution network of same structure (Chen et al. 2005) has been considered.

\section{Problem definition}

The objective of present study is to minimize the number of switching operations for restoration of power supply to all consumer's load and meeting the distribution system network constraints:

1. Let $\lambda_{1}$ (s) be the minimum number of switching operations. Let $\mathrm{N}_{\mathrm{sw}}$ be the maximum number of switches in the network. $\mathrm{X}$ is the position of switch during operartion. If a switch is opened from closed position or vice versa, the value of switch vector will be 1 and if there is no change in the status of switch, its value will be 0 .

2. The maximum feeder's loading $\lambda_{2}$ (s) shall be within the rating of current capacity limitation, if $\lambda_{2}$ (s) $\leq$ maximum (feeder lines loading). Similarly the maximum lateral loading, $\lambda_{3}(\mathrm{~s})$ is given by $\lambda_{3}(\mathrm{~s}) \leq$ maximum (lateral lines loading).

3. Restoration of maximum loads at faulted area.

4. Minimum switching operations in the restoration plan.

5. The load in feeder, laterals and transformers should be balanced as far as possible, and the overloading of electrical equipment should be avoided.

6. The reconfigured distribution system should be nearly close to the original system, and the radial structure of distribution system should be maintained.

\section{Mathematical model for reconfiguration}

In order to design and develop the strategic plans for reconfiguration and implement them effectively, the following model of constraints and equalities are presented: 


\section{Equalities/objective functions}

\section{Number of switching operations}

If $\lambda_{1}$ (S) defines the operations of the number of switches,

$$
\lambda_{1}(s)=\sum_{i=1}^{N_{s w}} X_{i}
$$

then, here, $X_{i}$ is switch state vector given by $\left[S_{1}, S_{2}, S_{3} \ldots, S_{N S w}\right], N_{s w}=$ The total switches that can be operated in the network under consideration, $\mathrm{X}_{\mathrm{i}}=$ status of the switch. The conditions for the switch status are: $\mathrm{X}_{\mathrm{i}}=1$, if switch is opened from closed position or vice versa, $X_{i}=0$, if status of switch is not changed. Minimum number of switching operations indicates that the system will be more stability.

\section{Maximum loading among backup feeders}

The maximum loading, $\lambda_{2}(\mathrm{~S})$ among supported feeder is given by Eq. (2):

$$
\lambda_{2}(S)=\operatorname{Max}\left(I_{F D_{i}}\right), \quad i=1,2, \ldots, N_{F D}
$$

$\mathrm{I}_{\mathrm{FD}_{\mathrm{i}}}$ represents the current over the supported feeder $\mathrm{FD}_{\mathrm{i}}$ after switching operations. $\mathrm{N}_{\mathrm{FD}}$ defines the number of supported feeders. To meet the constraints criteria, $\lambda_{2}(\mathrm{~s})$ shall be minimised. This objective function will give the most loaded backup feeder and by this we can have the remaining marginal load.

\section{Maximum loading among backup laterals}

Like loading criteria for feeders the supported laterals shall also meet the load criteria. This objective function will give the most loaded backup laterals. A lesser value of $\lambda_{3}(\mathrm{~s})$ is preferred.

$\lambda_{3}(\mathrm{~s})$ is the capacity of supported laterals and $\mathrm{LAT}_{\mathrm{i}}$ is the load current over the laterals after switching operation and $\mathrm{N}_{L A T}$ is the number of lateral branches. For techno-economic operation the $\lambda_{3}$ (S), Eq. (3) is desired to be minimized:

$$
\lambda_{3}(S)=\operatorname{Max}\left(I_{L A T_{i}}\right), \quad i=1,2, \ldots, N_{L A T}
$$

where $\lambda_{3}(\mathrm{~S})$ defines the supported laterals for maximum loading and $I_{L A T_{i}}$ defines current over of the supported lateral $\mathrm{LAT}_{\mathrm{i}}$ after switching operation. $\mathrm{N}_{\mathrm{LAT}}$ defines the number of laterals in the distribution network. The load on the laterals should be minimum for the best operating conditions during restoration.

\section{Unbalanced loading of feeders}

The feeders as well as laterals shall have the balanced loading of feeders and laterals. It is an important feature for line loss reduction and voltage stability criteria. Thus, the load unbalancing index of feeders and laterals can be computed using Eqs. (4) and (5) respectively.

$$
\lambda_{4}(S)=\sqrt{\sum_{i=1}^{N_{F D}}\left(L V_{F D_{i}}-L V_{F D}\right)^{2}}
$$


where, $L V_{F D_{i}}$ is percentage load level of feeder $F D_{i}$ and $L V_{F D}$ is percentage refrence load level which is given by Eq. (5)

$$
L V_{F D}=\frac{\sum_{i=1}^{N_{F D}} I_{F D_{i}}}{\sum_{i=1}^{N_{F D}} I R_{F D_{i}}} * 100
$$

In the above equation $\mathrm{IFD}_{\mathrm{F}}$ and $\mathrm{IR}_{\mathrm{FD}}$ represents the load current and rated load current of feeder. In order to improve the performance of the system the unbalancing loading index shall be as minimised.

\section{Unbalanced loading of laterals}

Similarly, the lateral branches unbalance load index $\lambda_{5}(\mathrm{~s})$ can be computed using equation:

$$
\lambda_{5}(S)=\sqrt{\sum_{i=1}^{N_{L A T}}\left(L V_{L A T_{i}}-L V_{L A T}\right)^{2}}
$$

where, $\mathrm{LV}_{\mathrm{LAT}_{\mathrm{i}}}$ is percentage load level of lateral $\mathrm{LAT}_{\mathrm{i}}$ and $\mathrm{LV}_{\mathrm{LAT}}$ is percentage reference load level which is given by Eq. (7) as:

$$
L V_{L A T}=\frac{\sum_{i=1}^{N_{L A T}} I_{L A T_{i}}}{\sum I R_{L A T_{i}}} * 100
$$

In the above equation, $I_{L A T_{i}}$ and $I R_{L A T_{i}}$ represents the load current and rated load current of lateral respectively. This objective function is used to determine the degree of unbalanced loading of laterals, therefore, less value of $\lambda_{5}(\mathrm{~s})$ is preferred.

\section{Maximum loading among backup transformer}

Transformer is the main source of power supply to feeders and laterals. Its maximum loading capacity and unbalanced loading index after the isolation of the fault needs to be computed and checked. These shall be as minimum as possible. The minimization of maximum loading of transformer due to supported feeders and laterals is desirable. Maximum loading of transformer, $\lambda_{6}(\mathrm{~s})$ is computed by Eq. (8) as:

$$
\lambda_{6}(S)=\operatorname{Max}\left(I_{T R S_{i}}\right), \quad i=1,2, \ldots, N_{T R S}
$$

\section{Unbalanced loading of transformer}

The unbalanced loading index of transformer, $\lambda_{7}$ (s) is given by Eq. (9), where,

$$
\lambda_{7}(s)=\sqrt{\sum_{i=1}^{N_{T R S}}\left(L V_{T R S_{i}}-L V_{T R S}\right)^{2}}
$$

where, $L V_{T R S i}$ is percentage load level of transformer $T R S_{i}$ and $L V_{T R S}$ is percentage reference load level which is given by Eq. (10)

$$
L V_{T R S}=\frac{\sum_{i=1}^{N_{T R S}} I_{T R S_{i}}}{\sum_{i=1}^{N_{T R S}} I R_{T R S}} * 100
$$


In the above equation $\mathrm{I}_{\mathrm{TRS}} \mathrm{i}_{\mathrm{i}}$ and $\mathrm{IR}_{\mathrm{TRS}}$ represents the load current and rated load current of transformer respectively. This gives the degree of unbalance loading of transformer for the backup and the value of this function should be minimum.

\section{Constraints}

To further optimize the switching operation for the reconfiguration of distribution system, the following constraints shall have to be met:

1. Open switch operation have been complemented by closed switch operation.

2. $\mathrm{I}_{\text {LATmin }}<\mathrm{I}_{\mathrm{j}}<\mathrm{I}_{\text {LATmax }}$

3. $\mathrm{I}_{\text {FEEDERmin }}<\mathrm{I}_{\mathrm{j}}<\mathrm{I}_{\text {FEEDERmax }}$

4. $\mathrm{I}_{\mathrm{TRS} \min }<\mathrm{I}_{\mathrm{j}}<\mathrm{I}_{\mathrm{TRS} \max }$

\section{Fuzzy grey method}

\section{Fuzzy multi criteria evolution}

The fuzzy logic method is a mathematical tool to make decision for vague and imprecise information in power system restoration problems (Chang 2008; Farahani et al. 2007; Gomes Flavio 2006; Gonzalez et al. 2012; Savier and Das 2007; Nagata et al. 1995; Pham et al. 2009; Wong and Lai 2000). Using fuzzy logic data base rules, a strategy with lesser switching operation and better load balance is achievable. Here, the linguistic terms like lesser, better etc. convey the vague nature of information. The restoration plan is considered more preferable if it involves fewer switching operations and better load balance. In restoration process, uncertainties arises when the feeder, lateral or transformer current is changing during the restoration process. These uncertainties can be taken into account using the fuzzy logic tool. It is based on rule-base (system operator experience), membership function of variable, and inference decision engine (IF THEN statement). One can consider the membership function of any type (triangular, sigmoid etc) but generally the fuzzy function is selected based on the nature of the problem. In the present study, three level (Low, Moderate and High) triangular fuzzy functions are considered to simplify the calculations during the restoration process, as shown in Fig. 1. "Appendix 2" presents the values of fuzzy membership function for different objective function. The fuzzy function transforms crisp value to fuzzy value which lie in the range $\{0,1\}$. Then using rule-base and fuzzy inference decision procedure, the fuzzy value related to each defined variable/objective function is computed. These output fuzzy values, after inference, are transferred back to crisp values using de-fuzzification methods (either centre of gravity method or centre of area method). In the consequents the fuzzy sets are low, moderate and high, and can be crisply defined as $1,0.5$ and 0 respectively. Further inference is drawn by calculating the real value of objective function. By real value we can get the firing strength in IF-THEN rule and the weighted average. By using Eq. (11), the crisp de-fuzzification value is derived.

$$
f_{i}^{*}=\frac{\sum_{j=1}^{N_{R}} \mu_{j} \times y_{j}}{\sum_{j=1}^{N_{R}} \mu_{j}}
$$




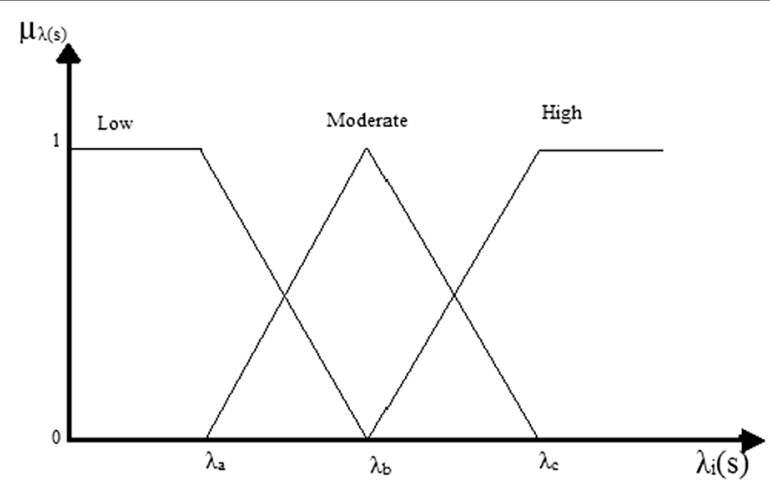

Fig. 1 Triangular fuzzy function

where, $\mu_{\mathrm{j}}$ and $y_{\mathrm{j}}$ are firing strengths of anticedents and consequences; $\mathrm{N}_{\mathrm{R}}$ represents the number of fuzzy rules. The value of $f_{i}^{* *}$ represent the fitness degree of objective function ' $f_{i}$ ' for each restoration plan. For example, the number of switching operations performed for the restoration plan 5 is 5 . The rules are as follows:

R1: IF $\lambda_{1}(\mathrm{~S})$ is low, THEN the plan is good.

$\mathrm{R} 2: \operatorname{IF} \lambda_{1}(\mathrm{~S})$ is moderate, THEN the plan is moderate.

R3: IF $\lambda_{1}(\mathrm{~S})$ is high, THEN the plan is bad

The rule strength of R1, R2 and R3 will be $0.5,0.5$ and 0 respectively for the plan 5 . After computing the rules, we use Eq. (11) to translate the rule results into real value by weighted average method. The singleton value for good, moderate and bad are $1,0.5$ and 0 respectively. The corresponding de-fuzzification value will be $(0.5 * 1+0.5 * 0.5+0 * 0) /$ $(0.5+0.5)=0.750$.

\section{Grey regression method}

Grey relation theory is based upon the concept that available information is incomplete and/or unknown. It is data analysis technique to solve the multicriteria decision making (MCDM). Such problems (MCDM) are difficult to solve using fuzzy logic tools (Wong and Lai 2000; Zhang and Zhengeai 2008; Cheng et al. 1998; Deng 1982; Dong et al. 2003; Huang and Huang 1996; Liu and Forrest 2007; Deng 1989; Song et al. 2002; Tsai et al. 2003; Wong and Lai 1999; Chang and Yeh 2005; Huang et al. 2008; Lin et al. 2008). The coefficient of grey relation (GRC) of $x_{i}$ with respect to $x_{0}$ for kth term is given in Chen et al. (2005).

$$
\gamma\left(x_{0}(k), x_{i}(k)\right)=\left\{\Delta_{\max }-\Delta_{\mathrm{o} i}(k)\right\} /\left\{\Delta_{\max }-\Delta_{\min }\right\}
$$

where, $x_{0}=\left(x_{0}(1), x_{0}(2), x_{0}(3), \ldots, x_{0}(\mathrm{n})\right), \mathrm{o}=1,2,3, \ldots, \mathrm{n}$, and $x_{i}=\left(x_{i}(1), x_{i}(2), x_{\mathrm{i}}(3), \ldots\right.$, $\left.x_{i}(\mathrm{~m})\right), \mathrm{i}=1,2,3, \ldots, \mathrm{m}$.

$$
\begin{aligned}
& \Delta_{\max }=\operatorname{Max}\left(x_{0}(k)-x_{i}(k)\right) \\
& \Delta_{\min }=\operatorname{Min}\left(x_{0}(k)-x_{i}(k)\right) \\
& \Delta_{\mathrm{o} i}(k)=\left|\left(x_{0}(k)-x_{i}(k)\right)\right|
\end{aligned}
$$


The GRG between each comparative sequence $x_{\mathrm{i}}$ and refrence sequence $x_{\mathrm{o}}$ is derived from average value of GRC. The order of relation between comparative and reference sequences is given by $\Gamma 0 i$. Higher value of $\Gamma 0 i$ means that the comparative sequence is more close to reference sequence than comparative sequence.

$$
\Gamma_{0 i}=\sum_{k=1}^{n} \frac{1}{n} \gamma\left(x_{0}(k), x_{i}(k)\right)
$$

In the next stage of the grey analysis, the GRA is used to measure the preference degree for all feasible restoration plans. The various steps for the fuzzy grey approach for ranking the restoration plans and selecting the satisfactory plan is presented in the fuzzy grey relation.

\section{Fuzzy-grey relation}

In order to overcome the limitations of decision conditions related to grey relational method and fuzzy logic tool limitations, the two decision making tools with incomplete and vague information are fused together to form a hybrid fuzzy-grey relational tool (Lin et al. 2008; Basu and George 2014; Pereira Junior et al. 2014; Shahsavari et al. 2014; Liu et al. 2015). This tool overcomes the limitations in the two methods, and make the decision making more relevant and effective. Based on the minimum value of $\lambda$, the optimized objective function is decided among various alternatives. Optimized $\lambda$ value is the best alternative switching operation sequence, loading on feeders, laterals and transformer. It provides the optimized solutions for decision making considering the various constraints and equalities. Choice of restoration plan is a type of multi criteria decision making problem which depends on all the objective functions and constraints considered. In this work we have tried to construct a measurement model via grey relational analysis to provide useful information and help system operator to make a right decision on the problem of service restoration.

Figure 2 represents the flow chart for the entire restoration algorithm. Starting with the on-off status of the switches, the feasible restoration plans are generated. Objective function values are computed using Eqs. (1)-(10) for the feasible plans. Further fitness degree of the objective function is evaluated using the fuzzy multicriteria evaluation method. The grey regression analysis (GRA) method is used to calculate the preference index of the restoration plans. Based on the grey regression grades (GRG) the plans are ranked according to their preference order. The addition of objective function's minimization of unbalanced loading of transformer gives the stable restoration plans for the considered network. This improves the system reliability and stability, leading to the improved performance of the system.

\section{Numerical application}

In order to show the utility of fuzzy-grey relation method for reconfiguration of distribution network, a distributed transformer as a source of supply is added to the network configuration (Chen et al. 2005).

The distribution system of Taiwan Power Company is considered and presented in Fig. 3, which has main feeders $\mathrm{YD}_{28}$ supplying power to LAT1, LAT2, LAT3, LAT4, 


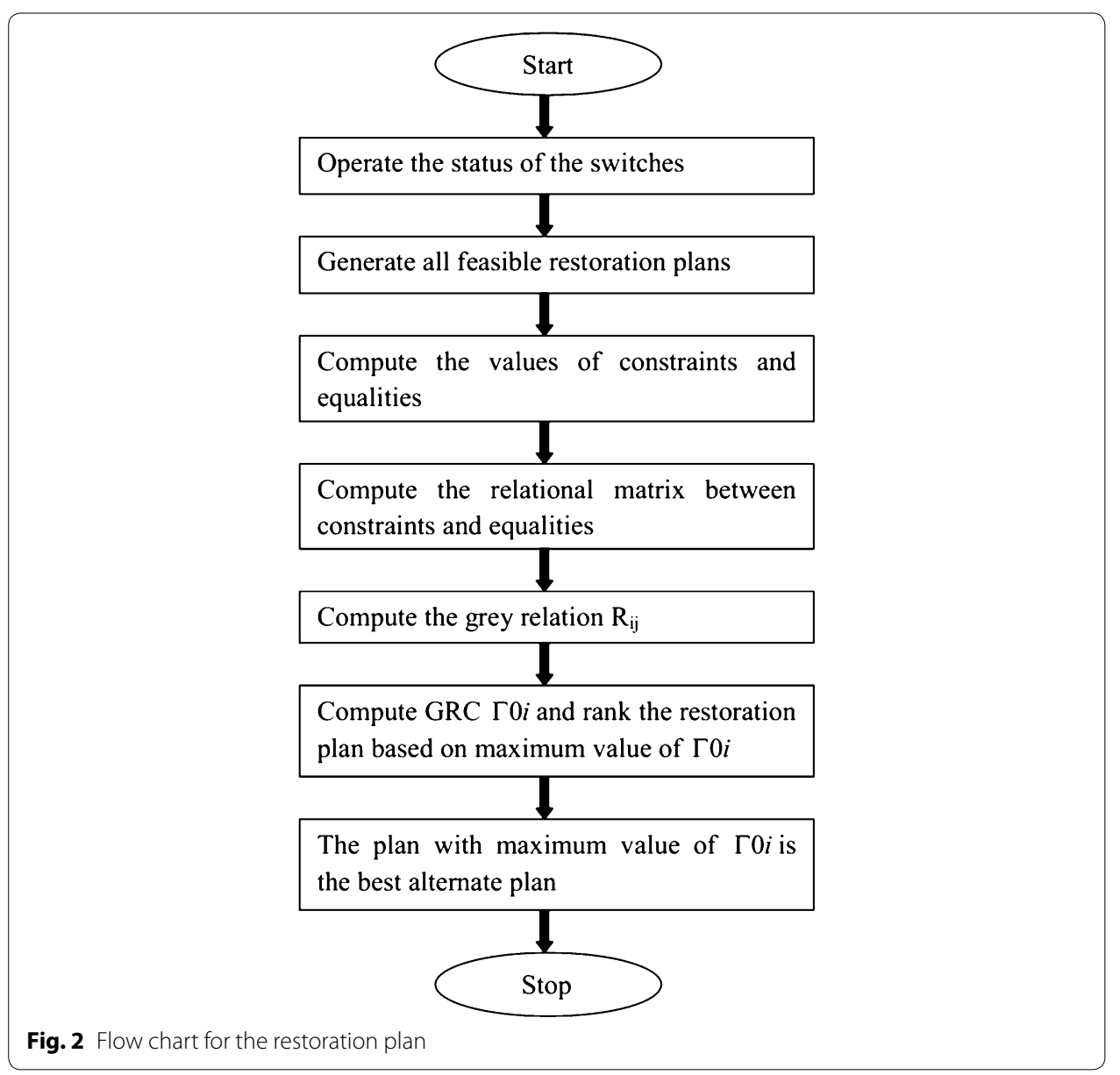

LAT5, LAT6, LAT7, LAT8 and LAT9. Each lateral has its supporting lateral (LAT10, LAT11, LAT12, LAT13, LAT14, LAT15, LAT16 and LAT17). These alternating laterals are connected to the main lateral with the help of switches. When a fault occurs in the system the switches operate to restore the out of service area. "Appendix 1" presents the pre-fault load current of feeders. "Appendix 2" presents the maximum capacity of each feeder, laterals, and the loading of transformer. The switch state vector, $\mathrm{X}$ comprises of the main switches $S_{W} i(i=1-9)$ and alternative switches $S_{W} j(j=1-8)$. Switch Sw9 always remain closed since lateral 9 is not connected with any other supporting lateral. To maintain the radial structure of the network, the switch open operation should be followed by switch close operation or vice versa. The switch pair for each restoration plan is given in Table 1 against each restoration plan based on the switching operation performed. The lateral, feeder and transformer loading is presented against the switching vector. All load values are in ampere. The maximum number of switching operations can be 8 , thus, the total number of possible restoration plans are $2^{8}=256$. The rated capacity of feeder, lateral, and transformer are assumed as 450,100, and $800 \mathrm{~A}$ respectively before the fault condition. Table 1 lists all the feasible restoration plans and the load currents on supporting lines after the restoration of supply. The 22 feasible restoration plans are selected from 256 possible restoration plans. The maximum switching 


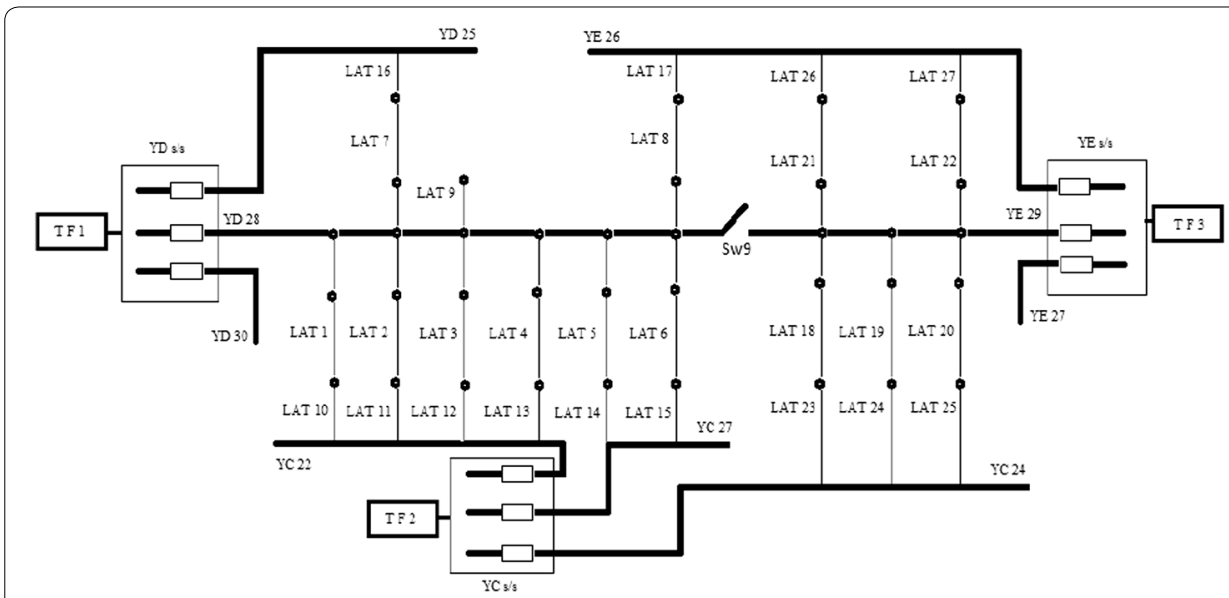

Fig. 3 Distribution system

Table 1 Load current of supporting components after restoration

\begin{tabular}{llllllllllllll}
\hline $\begin{array}{l}\text { Feasible } \\
\text { plan }\end{array}$ & $\begin{array}{l}\text { Switch pair } \\
\text { vector }\end{array}$ & $\mathbf{L} \mathbf{1 0}$ & $\mathbf{L 1 1}$ & $\mathbf{L 1 2}$ & $\mathbf{L 1 3}$ & $\mathbf{L 1 4}$ & $\mathbf{L 1 5}$ & $\mathbf{F}_{\mathbf{Y D}}$ & $\mathbf{F}_{\mathbf{Y C}}$ & $\mathbf{F}_{\mathbf{Y E}}$ & $\mathbf{T f 1}$ & $\mathbf{T f 2}$ & $\mathbf{T f 3}$ \\
\hline 1 & 11100000 & 76 & 84 & 86 & 37 & 34 & 31 & 441 & 352 & 260 & 370 & 352 & 441 \\
2 & 10110000 & 76 & 39 & 86 & 84 & 34 & 31 & 439 & 354 & 260 & 370 & 354 & 439 \\
3 & 01110000 & 51 & 84 & 86 & 84 & 34 & 31 & 419 & 374 & 260 & 370 & 374 & 419 \\
4 & 11001000 & 76 & 84 & 24 & 37 & 99 & 31 & 438 & 290 & 325 & 370 & 615 & 438 \\
5 & 00101000 & 51 & 39 & 86 & 37 & 99 & 31 & 446 & 282 & 325 & 370 & 607 & 446 \\
6 & 10101000 & 76 & 39 & 86 & 37 & 99 & 31 & 421 & 307 & 325 & 370 & 632 & 421 \\
7 & 01101000 & 51 & 84 & 86 & 37 & 99 & 31 & 401 & 327 & 325 & 370 & 652 & 401 \\
8 & 10011000 & 76 & 39 & 24 & 84 & 99 & 31 & 436 & 292 & 325 & 370 & 617 & 436 \\
9 & 01011000 & 51 & 84 & 24 & 84 & 99 & 31 & 416 & 312 & 325 & 370 & 637 & 416 \\
10 & 00111000 & 51 & 39 & 86 & 84 & 99 & 31 & 399 & 329 & 325 & 370 & 654 & 399 \\
11 & 11000100 & 76 & 84 & 24 & 37 & 34 & 98 & 436 & 290 & 327 & 370 & 617 & 436 \\
12 & 00100100 & 51 & 39 & 86 & 37 & 34 & 98 & 444 & 282 & 327 & 370 & 609 & 444 \\
13 & 10100100 & 76 & 39 & 86 & 37 & 34 & 98 & 419 & 307 & 327 & 370 & 634 & 419 \\
14 & 01100100 & 51 & 84 & 86 & 37 & 34 & 98 & 399 & 327 & 327 & 370 & 654 & 399 \\
15 & 10010100 & 76 & 39 & 24 & 84 & 34 & 98 & 434 & 292 & 327 & 370 & 619 & 434 \\
16 & 01010100 & 51 & 84 & 24 & 84 & 34 & 98 & 414 & 312 & 327 & 370 & 639 & 414 \\
17 & 00110100 & 51 & 39 & 86 & 84 & 34 & 98 & 397 & 329 & 327 & 370 & 656 & 397 \\
18 & 00001100 & 51 & 39 & 24 & 37 & 99 & 98 & 441 & 220 & 392 & 370 & 612 & 441 \\
19 & 10001100 & 76 & 39 & 24 & 37 & 99 & 98 & 416 & 245 & 392 & 370 & 637 & 416 \\
20 & 01001100 & 51 & 84 & 24 & 37 & 99 & 98 & 396 & 265 & 392 & 370 & 657 & 396 \\
21 & 00101100 & 51 & 39 & 86 & 37 & 99 & 98 & 379 & 282 & 392 & 370 & 674 & 379 \\
22 & 00011100 & 51 & 39 & 24 & 84 & 99 & 98 & 394 & 267 & 392 & 370 & 659 & 394 \\
\hline & & & & & & & & & & & &
\end{tabular}

operations possible are, therefore, 7 for the computations as per the switch state vector. Table 2 gives the values of all the objective functions. The corresponding data shown in Table 3 are obtained by fuzzy multi-criteria evaluation discussed in "Mathematical model for reconfiguration" section. This table gives us the values of reference sequence which is used further to calculate GRGs. the reference sequence selected for analysis is maximum value of fuzzy evaluation of objective functions: $\mathrm{X}_{0}=(0.750,0.2522,0.3469$, 


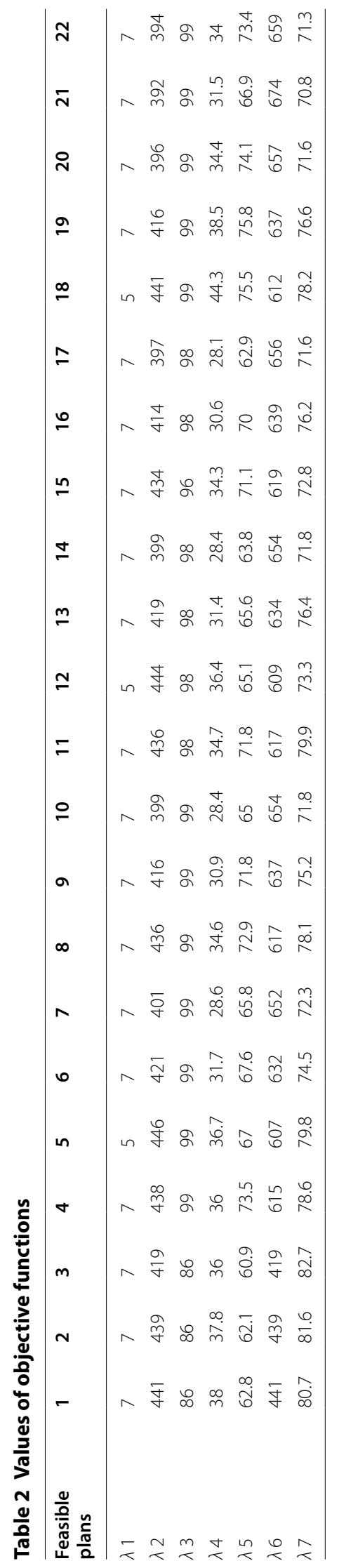


Table 3 Values of fuzzy evaluation data

\begin{tabular}{|c|c|c|c|c|c|c|c|}
\hline $\begin{array}{l}\text { Feasible } \\
\text { plans }\end{array}$ & $\lambda 1^{*}$ & $\lambda 2^{*}$ & $\lambda 3^{*}$ & $\lambda 4^{*}$ & $\lambda 5^{*}$ & $\lambda \sigma^{*}$ & $\lambda 7^{*}$ \\
\hline 1 & 0.625 & 0.0391 & 0.3469 & 0.620 & 0.372 & 0.6315 & 0.305 \\
\hline 2 & 0.625 & 0.0478 & 0.3469 & 0.622 & 0.379 & 0.6421 & 0.282 \\
\hline 3 & 0.625 & 0.1348 & 0.3469 & 0.640 & 0.391 & 0.7777 & 0.204 \\
\hline 4 & 0.625 & 0.0522 & 0.2143 & 0.650 & 0.266 & 0.4210 & 0.336 \\
\hline 5 & 0.750 & 0.0174 & 0.2143 & 0.633 & 0.330 & 0.3226 & 0.325 \\
\hline 6 & 0.625 & 0.1261 & 0.2143 & 0.683 & 0.324 & 0.1904 & 0.362 \\
\hline 7 & 0.625 & 0.2130 & 0.2143 & 0.714 & 0.324 & 0.1666 & 0.481 \\
\hline 8 & 0.625 & 0.0609 & 0.2143 & 0.654 & 0.271 & 0.1998 & 0.335 \\
\hline 9 & 0.625 & 0.1478 & 0.2143 & 0.691 & 0.282 & 0.1876 & 0.354 \\
\hline 10 & 0.625 & 0.2217 & 0.2143 & 0.716 & 0.350 & 0.1642 & 0.562 \\
\hline 11 & 0.625 & 0.0609 & 0.2245 & 0.653 & 0.282 & 0.1998 & 0.325 \\
\hline 12 & 0.750 & 0.0261 & 0.2245 & 0.636 & 0.349 & 0.1666 & 0.392 \\
\hline 13 & 0.625 & 0.1348 & 0.2245 & 0.659 & 0.344 & 0.1898 & 0.354 \\
\hline 14 & 0.625 & 0.2217 & 0.2245 & 0.716 & 0.362 & 0.1642 & 0.562 \\
\hline 15 & 0.625 & 0.0696 & 0.2245 & 0.657 & 0.289 & 0.1878 & 0.480 \\
\hline 16 & 0.625 & 0.1565 & 0.2245 & 0.694 & 0.300 & 0.1799 & 0.354 \\
\hline 17 & 0.625 & 0.2304 & 0.2245 & 0.719 & 0.371 & 0.1582 & 0.562 \\
\hline 18 & 0.750 & 0.0391 & 0.2143 & 0.557 & 0.245 & 0.2374 & 0.335 \\
\hline 19 & 0.625 & 0.1478 & 0.2143 & 0.615 & 0.242 & 0.1876 & 0.354 \\
\hline 20 & 0.625 & 0.2348 & 0.2143 & 0.656 & 0.259 & 0.1592 & 0.572 \\
\hline 21 & 0.625 & 0.2522 & 0.2143 & 0.685 & 0.331 & 0.0833 & 0.625 \\
\hline 22 & 0.625 & 0.2435 & 0.2143 & 0.667 & 0.266 & 0.1453 & 0.562 \\
\hline
\end{tabular}

$0.719,0.391,0.777,0.625)$. The GRG values computed using Eq. (13) are presented in Table 4 . The grey relation grades computed by Chen et al. (2005) are reproduced also in this table. After the GRA steps are completed, the preference ranking of feasible plans are derived with the related analysis and the ranking is presented in Table 5. From the table we can see that the plan 5 is having the highest rank. The plans get their ranking modified because of the addition of transformer objective functions. The loading of all the transformer present in the distribution system is graphically presented in Fig. 4. Additional objective function increases the stability of the system as the unbalancing of the transformer load can also be handled. The new plans are compared with the earlier ones in Fig. 5. Higher the number of objective functions more is the stability of the system as more parameters are considered. The difference of old and new GRG is calculated in Table 4. Further, mean of difference of new and old GRG is calculated, which comes out to be 0.1092 . This means that the system performance has increased by $1.09 \%$ with new GRG. The restoration plans are ranked according to the new GRG values. If the current exceeds in a particular element, it could fail and the current would be shunted to other network element which eventually may fail also. Here all equipments are considered so if feeder gets overloaded, it can transfer load to lateral and it can shift the load to the transformer and system gets more stable. Entire restoration algorithm consists of the fuzzy evaluation and fuzzy grey multicriteria given by flow chart. The inclusion of transformer loading parameters in fuzzy analysis makes the system more stable as more parameters are restored. In previous work, feeder and laterals were restored but in this 
Table 4 Test result of grey relational grade

\begin{tabular}{|c|c|c|c|}
\hline Feasible plan & GRG (old) & GRG (new) & Difference in GRG \\
\hline 1 & 0.612 & 0.6612 & 0.0492 \\
\hline 2 & 0.6277 & 0.8304 & 0.2027 \\
\hline 3 & 0.7263 & 0.8231 & 0.0968 \\
\hline 4 & 0.4446 & 0.7221 & 0.2775 \\
\hline 5 & 0.5624 & 0.9723 & 0.4099 \\
\hline 6 & 0.5862 & 0.7869 & 0.2007 \\
\hline 7 & 0.7011 & 0.6582 & -0.0429 \\
\hline 8 & 0.4611 & 0.8806 & 0.4195 \\
\hline 9 & 0.576 & 0.6205 & 0.0445 \\
\hline 10 & 0.718 & 0.4381 & -0.2799 \\
\hline 11 & 0.4779 & 0.6997 & 0.2218 \\
\hline 12 & 0.5968 & 0.7461 & 0.1493 \\
\hline 13 & 0.6212 & 0.576 & -0.0452 \\
\hline 14 & 0.7369 & 0.5327 & -0.2042 \\
\hline 15 & 0.4944 & 0.4994 & 0.005 \\
\hline 16 & 0.6101 & 0.6113 & 0.0012 \\
\hline 17 & 0.7539 & 0.6827 & -0.0712 \\
\hline 18 & 0.4435 & 0.7321 & 0.2886 \\
\hline 19 & 0.4767 & 0.7261 & 0.2494 \\
\hline 20 & 0.6001 & 0.8626 & 0.2625 \\
\hline 21 & 0.7011 & 0.8251 & 0.124 \\
\hline 22 & 0.6173 & 0.6621 & 0.0448 \\
\hline
\end{tabular}

Table 5 Rank before and after restoration

\begin{tabular}{|c|c|c|c|c|c|c|c|c|c|c|c|}
\hline Feasible plan & 1 & 2 & 3 & 4 & 5 & 6 & 7 & 8 & 9 & 10 & 11 \\
\hline $\begin{array}{l}\text { Grey relational } \\
\text { grade }\end{array}$ & 0.6612 & 0.8304 & 0.8231 & 0.7221 & 0.9723 & 0.7869 & 0.6582 & 0.8806 & 0.6205 & 0.4381 & 0.6997 \\
\hline Rank before fault & 10 & 7 & 3 & 21 & 16 & 14 & 5 & 20 & 15 & 4 & 18 \\
\hline $\begin{array}{l}\text { Rank after restora- } \\
\text { tion }\end{array}$ & 16 & 4 & 6 & 11 & 1 & 7 & 17 & 2 & 18 & 22 & 12 \\
\hline Feasible plan & 12 & 13 & 14 & 15 & 16 & 17 & 18 & 19 & 20 & 21 & 22 \\
\hline $\begin{array}{l}\text { Grey relational } \\
\text { grade }\end{array}$ & 0.7461 & 0.576 & 0.5327 & 0.4994 & 0.6113 & 0.6827 & 0.7321 & 0.7261 & 0.8626 & 0.8251 & 0.6621 \\
\hline Rank before fault & 13 & 8 & 2 & 17 & 11 & 1 & 22 & 19 & 12 & 6 & 9 \\
\hline $\begin{array}{l}\text { Rank after restora- } \\
\text { tion }\end{array}$ & 8 & 19 & 20 & 21 & 14 & 13 & 9 & 10 & 3 & 5 & 15 \\
\hline
\end{tabular}

work, transformer is included and restored after the fault which increases the stability and reliability of the system.

In this paper, the objective functions are considered so as to optimize the operation of switches and loading of feeders, laterals as well as on transformers and minimization of unbalanced loading index of feeders, laterals and transformer after switching operation. The constraints in the restoration process to be considered are: (a) maintain the radial structure of the network, (b) no overloaded equipment and (c) higher priority customers should always be supplied first. The result shows that inclusion of the transformer current limits has changed the ranking of plans. The system becomes more reliable with 

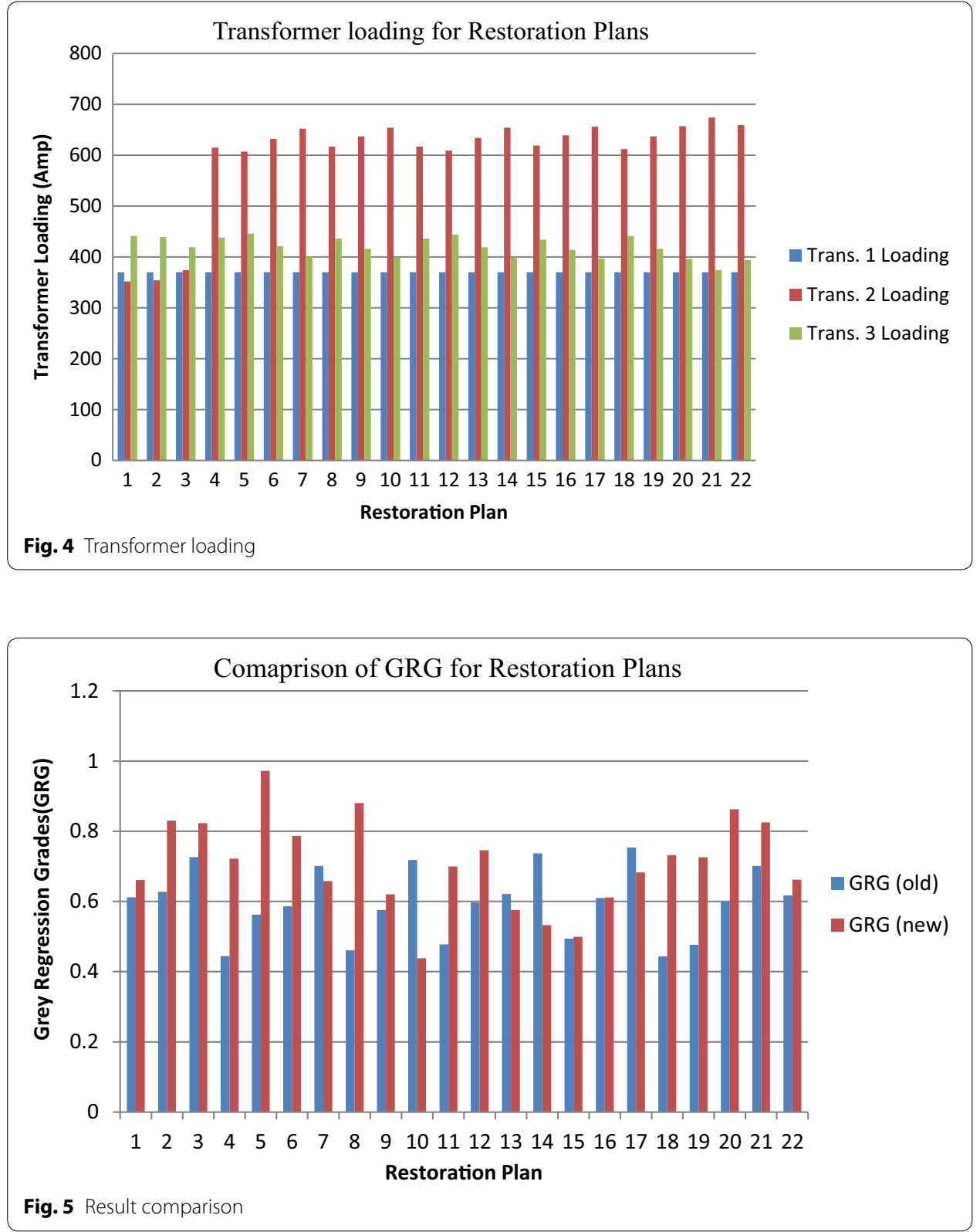

the minimization of unbalanced loading of transformer current as there is no scope for exceeding the limits during restoration plans. Feasible plans which consider more objective functions make the system more reliable. The reliability and stability of the restored network has increased by $1.09 \%$. The priority customers can be supplied first on the basis of the preference index plans during partial blackout or full blackout. The consumer loads which are not energized may be fed by the supporting feeders in the neighbourhood via on-off switches. The result shows that restoration process is done using minimum number of switching operations. Safety and operability of transformer, laterals and feeders is taken up by maintaining the line currents within the operational limits of power system components. 
The topology of distribution system is maintained radial before and after implementing the restoration plans. A switch-opened operation is always followed by a switchclose operation, after every switching operation.

\section{Conclusion}

Simulation studies for restoration of distribution system are carried out considering multi-objective problem and fuzzy-grey algorithm. Transformer loading has been considered as an additional objective function in the optimization problem. The result shown is more stable and reliable because more are the objective functions, greater is the stability. Various strategies are derived based on rank. The best strategy is the one with the highest rank. The studies are useful for system operator in taking right decision during the restoration process. The rank of restoration plans is given which makes this method effective and very promising. The studies are useful for electric utilities/power distribution company to improve the customer services and revenue returns.

\section{Discussion and future work}

This research work has proposed an intelligent restoration algorithm for the distribution system using fuzzy grey combination. The computation implementation is done by adding the unbalance loading of transformer to the Taiwan Power Distribution network. The result shows that the stability of system has improved with the new additional objective functions. The fuzzy multicriteria evaluation gives the optimization values for various objective functions and using grey regression analysis the ranking of plans has been done. This can help in service restoration of priority based customers. The intelligent algorithm is capable of fulfilling the requirements of smart grid such as stability, automation and reliability. The power system automation enables rapid diagnosis and precise solutions to the particular network outages. The proposed algorithm can be useful in making the restoration process automatic with the predecided rank of plans.

\section{Author's contribution}

All the research work and experimental analysis has been done by first author and layout and formatting of the manuscript has been done by co-authors. All authors read and approved the final manuscript.

\section{Author details}

1 Jamia Millia Islamia, New Delhi, Delhi, India. ${ }^{2}$ Department of Electrical Engineering, Jamia Millia Islamia, New Delhi, Delhi, India. ${ }^{3}$ IRD, Maharaja Agrasen Institute of Technology, New Delhi, Delhi, India.

\section{Acknowledgements}

We are thankful to Prof. Majid Jamil (HOD, Electrical Engg. Deptt., Jamia Millia Islamia) for his help as and when required.

The authors have no source of funding from anywhere.

Competing interest

The authors declare that they have no competing interests.

\section{Appendix 1}

See Table 6.

Table 6 Pre fault load current of laterals

\begin{tabular}{llllllllllllllllll}
\hline Lateral & $\mathbf{1}$ & $\mathbf{2}$ & $\mathbf{3}$ & $\mathbf{4}$ & $\mathbf{5}$ & $\mathbf{6}$ & $\mathbf{7}$ & $\mathbf{8}$ & $\mathbf{9}$ & $\mathbf{1 0}$ & $\mathbf{1 1}$ & $\mathbf{1 2}$ & $\mathbf{1 3}$ & $\mathbf{1 4}$ & $\mathbf{1 5}$ & $\mathbf{1 6}$ & $\mathbf{1 7}$ \\
\hline Current & 25 & 45 & 62 & 47 & 65 & 67 & 60 & 55 & 20 & 51 & 39 & 24 & 37 & 34 & 31 & 60 & 80 \\
\hline
\end{tabular}




\section{Appendix 2}

See Table 7.

Table 7 Values of fuzzy function for objective function

\begin{tabular}{llrrr}
\hline S. no & Objective function & $\boldsymbol{\lambda}_{\boldsymbol{a}}$ & $\boldsymbol{\lambda}_{\boldsymbol{b}}$ & $\boldsymbol{\lambda}_{\boldsymbol{c}}$ \\
\hline 1 & Number of switching operation & 1 & 9 & 17 \\
2 & Loading among supported feeder (A) & 220 & 345 & 450 \\
3 & Loading among supported laterals (A) & 24 & 76 & 120 \\
4 & Unbalance loading index of feeders & 0 & 50 & 100 \\
5 & Unbalance loading index of laterals & 320 & 500 & 100 \\
6 & Loading among supported transformer (A) & 40 & 70 & 100 \\
7 & Unbalance loading index of transformers & 40 & 580 \\
\hline
\end{tabular}

Received: 28 March 2016 Accepted: 11 July 2016

Published online: 26 July 2016

\section{References}

Basu KP, George M (2014) Maintaining balanced three-phase load voltage during single-phase auto-reclosing in medium voltage distribution lines. IET Gener Transm Distrib Mag 5(3):798-802

Berdandon P, Sperndio M, Garcia J (2011) AHP decision making algorithm to allocate remotely controlled switches in the distribution networks. IEEE Trans Power Deliv 26(3):1884-1892

Chang CF (2008) Reconfiguration and capacitor placement for loss reduction of distribution system by ant colony search algorithm. IEEE Trans Power Syst 23(4):1747-1755

Chang K-C, Yeh M-F (2005) Grey relational analysis based approach for data clustering. IEE Proc Vis Image Signal Process 152(2):165-172

Chen WH, Liu CW, Tsai MS (2001) Fast fault section estimation in distribution substations using matrix-based cause-effect networks. IEEE Trans Power Deliv 16(4):522-527

Chen WH, Tsai MS, Kuo HL (2005) Distribution system restoration using the hybrid fuzzy grey method. IEEE Trans Power Syst 20(1):199-205

Cheng CS, Hsu YT, Wu CC (1998) Grey neural network. IEICE Trans Fundam Electron Commun Comput Sci $81(11): 2433-2442$

Deng JL (1982) Control problems of grey systems. Syst Contr Lett 1:288-294

Deng JL (1989) Introduction to grey system theory. J Grey Syst 1:1-24

Dong M, Yan Z, Taniguchi Y (2003) Fault diagnosis of power transformer based on model-diagnosis with grey relation. In: 7th international conference on properties and applications of dielectric materials, pp 1158-1161

Farahani V, Vahidi B, Askarian H (2007) Reconfiguration and capacitor placement simultaneously for energy loss reduction based on an improved reconfiguration method. IEEE Trans Power Syst 18(1):587-595

Feltes WJ et al. (2006) Some considerations in the developments of restoration plans for electric utility serving large metropolitan areas. IEEE Trans Power Syst 21(2):909-915

Fukuyama Y, Chiang HD (1995) A parallel genetic algorithm for service restoration in electric power distribution systems. In: Proceedings of IEEE conference on fuzzy system, pp 275-282

Gomes Flavio V et al. (2006) A new distribution system reconfiguration approach using optimum power flow and sensitivity analysis for loss reduction. IEEE Trans Power Syst 21(4):1616-1623

Gonzalez A, Echavarren FM, Rouco L, Gomez T (2012) A sensitivities computation method for reconfiguration of radial networks. IEEE Trans Power Syst 27(3):1294-1301

Hsiao YT, Chien CY (2000) Enhancement of restoration service in distribution systems using a combination fuzzy-GA method. IEEE Trans Power Syst 15(4):1394-1400

Hsu YY, Huang HM, Kuo HC, Peng SK, Chang CW, Chang KJ, Yu HS, Chow CE, Kuo RT (1992) Distribution system service restoration using a heuristic search approach. IEEE Trans Power Deliv 7(2):734-740

Hsu YY, Kuo HC (1994) A heuristic based fuzzy reasoning approach for distribution system service restoration. IEEE Trans Power Deliv 9(2):948-953

Huang Y-P, Chang T-W, Sandnes FE (2008) Efficient shape-based image retrieval based on grey relational analysis and association rules. Int J Pattern Recogn Artif Intell 22(4):711-732

Huang YP, Huang CC (1996) The integration and application of fuzzy and grey modeling methods. Fuzzy Sets Syst 78:107-119

Lee SJ, Lim S, Ahn BS (1998) Service restoration of primary distribution systems based on fuzzy evaluation of multicriteria. IEEE Trans Power Syst 13(3):1156-1163 
Lim S, Lee S, Choi MS (2006) Service restoration methodology for multiple fault case in distribution systems. IEEE Trans Power Syst 21(4):1638-1644

Lin W-M, Huang C-H, Lin C-H, Chen C-M, Wang L-W (2008) Restoration strategy for secondary power network with grey relational analysis. IET Gener Transm Distrib 2(2):167-174

Liu W, Lin ZZ (2012) Intuitionistic fuzzy choquet integral operator based approach for black start decision making. IET Gener Transm Distrib 6(5):378-386

Liu W, Lin Z, Wen F, Ledwich G (2015) Analysis and optimisation of the preferences of decision-makers in black-start group decision-making. IET Gener Transm Distrib 7(1):14-23

Lotfifard S, Kezunovic M, Mousavi MJ (2011) Voltage sag data utilization for distribution fault location. IEEE Trans Power Deliv 26(2):1239-1246

Liu SF, Forrest J (2007) Advances in grey system theory and its applications. In: Proceedings of ieee international conference on grey systems and intelligent services, pp 1-6

Ma TK, Liu CC, Tsai MS, Rogers R, Muchlinski SL, Dodge J (1992) Operational experience and maintenance of an on-line expert system for customer restoration and fault testing. IEEE Trans Power Syst 7(2):835-842

Nagata T, Sasaki H (2002) A multi-agent approach to power system restoration. IEEE Trans Power Syst 17(2):457-462

Nagata T, Sasaki H, Yokoyama R (1995) Power system restoration by joint usage of expert system and mathematical programming. IEEE Trans Power Syst 10(3):1473-1479

Pereira Junior BR, Cossi AM, Contreras J, Sanches Mantovani JR (2014) Multiobjective multistage distribution system planning using tabu search. IET J Gener Transm Distrib 8(1):35-45

Pham TTH, Besanger Y, Hadjsaid N (2009) New challenges in power system restoration with large scale of dispersed generation insertion. IEEE Trans Power Syst 24(1):398-406

Savier JS, Das D (2007) Impact of network reconfiguration on loss allocation of radial distribution systems. IEEE Trans Power Deliv 22(4):331-338

Shahsavari A, Mazhari SM, Fereidunian A, Lesani H (2014) Fault indicator deployment in distribution systems considering available control and protection devices: a multi-objective formulation approach. IEEE Trans Power Syst 29(5):2359-2369

Song B, Yu P, Luo Y, Wen X (2002) Study on the fault diagnosis of transformer based on the grey relational analysis. In: Proceedings on power system technology, vol 4, pp 2231-2234

Tsai $\mathrm{CH}$, Chang CL, Chen L (2003) Applying grey relational analysis to the vendor evaluation model. Int J Comput Internet Manag 11(3):45-53

Tsai MS, Liu CC, Mesa VN, Hartwell R (1993) IOPADS (Intelligent operational planning aid for distribution systems. IEEE Trans Power Deliv 8(3):1562-1569

Wong CC, Lai HR (2000) A new grey relational measurement. J Grey Syst 12:341-346

Wong CC, Lai HR (1999) Generating fuzzy control rules by a clustering algorithm based on a grey relational measure. In: Proceeding on IEEE international fuzzy systems conference, pp 22-25

Zhang D, Zhengeai F (2008) Joint optimization for power loss reduction in distribution systems. IEEE Trans Power Syst 23(1):161-169

\section{Submit your manuscript to a SpringerOpen ${ }^{\circ}$ journal and benefit from:}

- Convenient online submission

- Rigorous peer review

- Immediate publication on acceptance

Open access: articles freely available online

- High visibility within the field

- Retaining the copyright to your article

Submit your next manuscript at $\boldsymbol{\nabla}$ springeropen.com 